\title{
Un viaje seguro: Las representaciones de pies y aves en la ico- nografía de época ibérica.
}

Lourdes Prados Torreira. UAM

Lourdes.prados@uam.es

\section{Resumen}

En este artículo, a partir del estudio de un exvoto de bronce ibérico del Museo de Barcelona, procedente posiblemente del Santuario de Castellar (Jaén), que representa un pie izquierdo coronado por una paloma, se analizan los hallazgos tanto de pies como de aves en el mundo ibérico. El ave, símbolo de la divinidad femenina, sanciona con su presencia los ritos de paso.

Palabras-clave: Arqueología Ibérica - Iconografía- Poblados- Necrópolis - Santuarios - Aves - Pies

\section{Abstract}

In this paper we present the study of an Iberian bronze, that represents a foot with a dove at the top, coming probably, from the Iberian sanctuarie of Castellar, in Jaén. We analyze other examples of representations of feet and birds in different Iberian archaeological contexts. The dove represents a female divinity that protects with her presence the transition rites.

Key-words: Iberian Archaeology - Iconography- - Cemeteries - Sanctuaries - birds feet

Resulta complejo tratar de escribir un artículo como homenaje a R. Lucas, ya que para sus compañeros del Departamento de Prehistoria y Arqueología de la UAM y en muchos casos, como es el mío, también antiguos alumnos, nos resulta difícil pensar que ya no está con nosotros. Sin embargo, siguiendo el espíritu que siempre la acompañó intentaremos abordar estas líneas con alegría y con un brindis, como ella quiso que la recordáramos. He tratado de buscar un tema que hubiera sido de su interés, confío en haberlo encontrado.

Los estudios sobre iconografía ibérica han recibido un gran impulso en los últimos años siguiendo, en gran medida, las pautas de la investigación de otros países mediterráneos y, en particular de Francia e Italia. En ese protagonismo podemos destacar algunas obras, de carácter colectivo, publicadas en los últimos años (Olmos et alii, 1992; Olmos 1996; Olmos y Santos 1997; Aranegui 1997; Tortosa y Santos 2003; Izquierdo et alii 2004...) En ellas, se trata de buscar, de determinar y descodificar un lenguaje que va más allá de su simple representación en diferentes tipos de soporte y contextos.

Hace ya algunos años publiqué en un artículo, "Los ritos de paso y su reflejo en la toreútica ibérica" (Prados 1996, fig. 6 y pág 279), una pieza muy interesante del Museo de Barcelona, que creo que por su importancia iconográfica, merece un análisis más detallado.

\section{Pie coronado por un ave.}

Se trata de una pequeña pieza de bronce conservada en el Museo Arqueológico de Barcelona, con el $\mathrm{n}^{0}$ de inventario 27.536, posiblemente originaria de uno de los dos santuarios ibéricos de Jaén, quizá de Castellar, ya que se encontraba en dicho museo junto a otros exvotos procedentes de este santuario.

Representa un pie izquierdo, quizá calzado, 


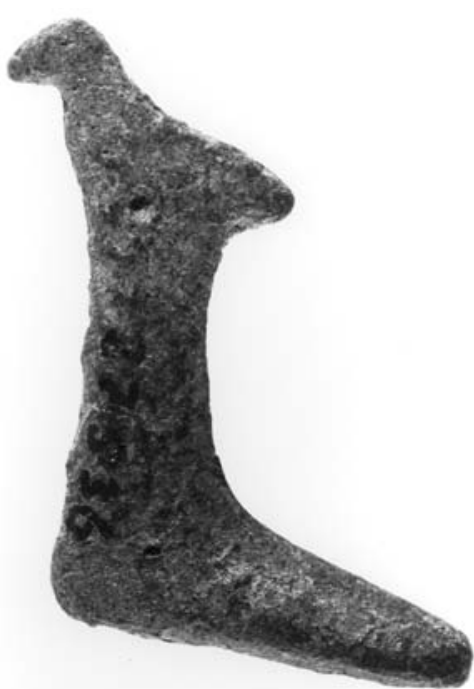

FIGURA 1- Pie coronado por una paloma. $N^{0}$ Inv. 27.536 Museo Arqueológico de Barcelona. Fotog. Museo Arqueológico de Barcelona.

aunque su estado de conservación impide asegurarlo con certeza, coronado por un ave que interpretamos, como una paloma, que mira en sentido contrario al de la marcha. (fig 1.)

$\mathrm{El}$ interés de esta pieza, reside en aunar en un mismo objeto dos tipos de imágenes conocidas en el mundo ibérico, las representaciones de pies y de aves y, si no me equivoco, creo que se trata hasta la fecha del único ejemplo en donde ambas iconografías aparecen de forma conjunta.

Por ello, voy a intentar hacer una recopilación de las representaciones de pies y aves en la cultura ibérica, para intentar posteriormente valorar su posible significado.

\section{I- LAS REPRESENTACIONES PODOMORFAS EN EL MUNDO IBÉRICO}

Existen ya algunos trabajos donde, desde distintos puntos de vista e intereses, se ha hecho una cierta recopilación o análisis de la aparición de este tipo de representaciones en el ámbito ibérico. En 1991, a partir del estudio de los exvotos anatómicos de los santuarios ibéricos, yo misma hacía una recopilación de la aparición de piernas y pies con el sentido de ofrendas de carácter salutífero en distintos santuarios ibéricos (Prados 1991; pág 319- 325; Figs 1 y 2.). Años más tarde, a propósito de los ritos de paso y en concreto del posible significado de la pieza que nos ocupa, recogía varios ejemplos de estas representaciones

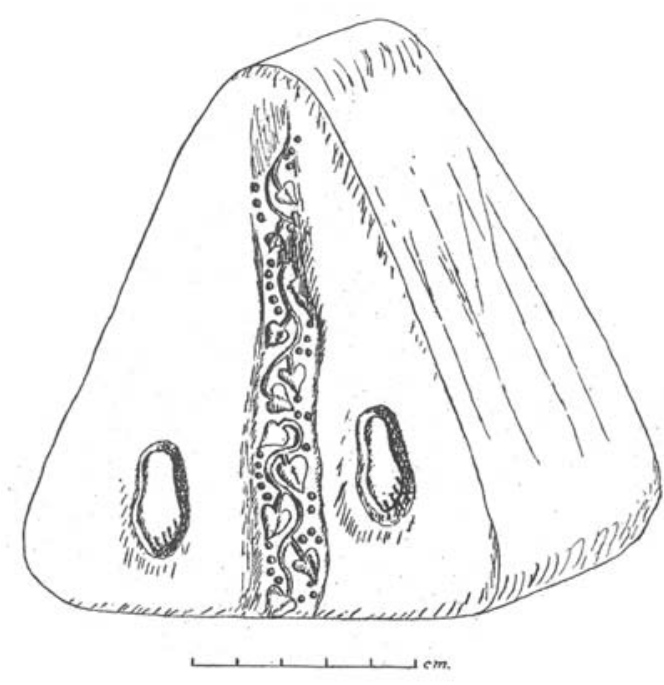

FIGURA 2- Prisma cerámico con representación de pies. Santuario de El Cigarralejo (según Cuadrado 1950)

(Prados 1996: 279). Del mismo modo, volvía a incidir sobre alguno de estos aspectos en otro artículo sobre santuarios de frontera (Prados 1998: 185). Posteriormente R. Lucas, en su artículo sobre el sexo de los dioses: las divinidades escondidas entre los exvotos de "El Cigarralejo" (Mula, Murcia)", a partir de la representación de un prisma cerámico con representación podomorfa de este santuario murciano, recoge también otros ejemplos del ámbito ibérico (2003: 198-199). Asimismo, Pérez-Ballester y Gómez Bellard (2004) al estudiar las imitaciones de vasos plásticos en el mundo ibérico recopilan tanto los prototipos de vasos plásticos en forma de pie y de ave en barniz negro, como sus imitaciones ibéricas ${ }^{1}$. Recientemente, a raíz del estudio del depósito votivo de "La Carraposa" (Valencia) donde aparece la representación de unos pies en arcilla, se hace referencia a algunas de estas imágenes (Pérez Ballester y Borredá Mejías, 2004)

Basándonos en estos estudios previos vamos, por tanto, a intentar mostrar un panorama de los yacimientos y contextos dónde aparecen estas representaciones de pies en la cultura ibérica.

\section{Santuarios}

El Cigarralejo (Mula, Murcia).

De este santuario proceden distintas piezas: Bloque de barro prismático localizado en la ladera E. al pie de la roca que actúa de muro externo 
de las habitaciones 1 y 2 (Fig. 2) (Cuadrado, 1950, 49-51 y fig. 11; Lucas 1981 y 2003: 198-199 y fig. 2: 4). Esta pieza fue estudiada por Lucas en los últimos años, quien recoge fielmente la descripción de Cuadrado (1950, 51): "se trata de un bloque prismático de barro muy bien cocido, de color ocre rosáceo. Dos de sus caras forman triángulos isósceles ...El centro de la cara mayor lleva estampada una guirnalda vegetal de $15 \mathrm{~mm}$. de ancho representando un tallo sinuoso con hojas de hiedra dirigidas hacia la base y serie de puntos entre las hojas, a manera de frutos o semillas. Hacia la base, a uno y otro lado de la guirnalda, se estamparon dos pies izquierdos, utilizando la misma estampilla con distinta presión" (Lucas 2003: 198-99).

En la H. 5 se localizó la parte superior de una pesa de telar piramidal con la impresión de un pie encima (Cuadrado 1950, 38; Lucas 2003, 199).

Por último, Cuadrado nos habla de dos pies reproducidos sobre una placa de arcilla: la pieza consiste en un ladrillo de $138 \mathrm{~mm}$. $\times 115 \times 25 \mathrm{~mm}$. Los pies están juntos y pertenecen a un mismo individuo...Sobre la cara de ambos pies se han socavado dos cazoletitas... En cuanto a su posible objeto, nos atrevemos a suponer sirviesen para depositar una ofrenda: monedas, anillos, perfumes o tal vez fuesen una representación del mal sufrido (Cuadrado 1950: 179-180)

Collado de los Jardines (Sta. Elena, Jaén)

En este santuario, situado en pleno desfiladero de Despeñaperros, los exvotos anatómicos representan un 7\% del total de bronces del yacimiento y entre ellos, junto a ojos, dentaduras, brazos y manos, cabezas o falos y úteros, predominan claramente las representaciones de piernas y pies, unos 40 en total, incluyendo algunas láminas de metal (Prados 1991: 324-325).

Cueva de La Lobera (Castellar, Jaén)

Lantier nos hace una relación de los diferentes exvotos que representan partes del cuerpo humano aparecidos en este santuario, sin que figure el pie coronado por un ave objeto de nuestro estudio. Junto a manos, ojos, senos, falos e incluso intestinos, menciona también la aparición de piernas. Según estos datos y las fotografías de su publicación, pudimos hacer un recuento de 32 piernas y pies (Lantier 1917: 93-94; lám XVIII; Prados 1991: 328). En las excavaciones efectuadas con posterioridad no se encontraron exvotos de este tipo (Fernández Chicarro; Nicolini, 1983; Nicolini et alii 2004)

Torreparedones (Castro del Río Córdoba)

En este santuario, donde los exvotos en piedra caliza representan mayoritariamente imágenes de mujeres, existe una proporción bastante alta de representaciones de miembros inferiores del cuerpo humano, unos 39 en total. Se trata, como es conocido, de un santuario extramuros construido a fines del siglo III o inicios del II a.n.e, aunque no se rechaza la posibilidad de que se edificase sobre un espacio sagrado de carácter natural, con la posible existencia de edificaciones anteriores. (Morena López, 1989: 45 y láms L, LI y LII; Prados 1991; Morena 1997; Vaquerizo 1997; Cunliffe y Fernández-Castro 1999: 100106; Fernández-Castro y Cunliffe 2002). El edificio, el más antiguo de los documentados hasta ahora se reformó, aproximadamente, un siglo después y en un momento difícil de precisar de la segunda mitad del I a.n.e., fue reemplazado por otro de carácter más monumental, que estuvo en uso hasta el siglo I d.n.e., aunque este santuario sigue planteando cuestiones de cronología (Morena 1997: 281; Almagro-Gorbea y Moneo 2000: 24; Marín y Belén 2003: 178).

\section{Alarcos (C. Real)}

Los aproximadamente 60 exvotos de bronce ibéricos del Oppidum de Alarcos, aparecieron en los restos de una estructura rectangular situada a extramuros de la muralla del castillo medieval. Junto a estas piezas, en su mayoría figuras humanas, apareció un miembro inferior (Caballero y Mena, 1987, 620, fig.11), así como pequeños recipientes, páteras, cerámica griega y campaniforme, fíbulas de bronce, varios punzones de hueso, un semis de Cástulo, etc. Este edificio se considera un santuario extramuros (Juan et alii 1994), tal vez de entrada ( Moneo 2003, 162). Su momento álgido se sitúa a fines del III o comienzos del II a C.

\section{La Carraposa (Valencia)}

En este depósito votivo, de finales del s. II o comienzos del I a C, se ha localizado un pie de terracota que, según sus estudiosos, podría estar calzado con una bota. (Pérez Ballester y Borredá Mejías 2004: 299)

\section{Cancho Roano (Zalamea La Serena, Badajoz)}

En el que se ha denominado santuario "B" de Cancho Roano, datado entre finales del VI y principios del siglo $\mathrm{V}$ a.C. se hallaron varios agujeros practicados en el suelo en forma de pie. Asimismo, en la habitación principal o H-7, junto al altar en forma de piel de toro extendida, aparecieron cuatro pies alineados por lo que se considera que probablemente éstos se utilizaron a modo de pies derechos, para soportar una cubierta de madera, dado que al otro lado del altar se hallaron cuatro agujeros aunque, en esta ocasión, circulares. 
Lo más llamativo de estos pies, así como de los otros aparecidos en las habitaciones laterales donde también se hallaron sendos altares de adobe, es que en su fondo contenían un hueso de caballo cada uno, lo que le confiere un significado muy especial si tenemos en cuenta que la presencia del caballo es constante en este santuario. En concreto en el último edificio, Cancho Roano "A", se halló en el foso, junto a otro tipo de animales, una importante cantidad de caballos sacrificados con las cabezas cortadas (Celestino comunicación oral y 1997, 371; 2001: 27; Lucas 2003: pág. 205, nota 11)

\section{Cádiz)}

La Algaida (Sanlúcar de Barrameda,

En este interesante santuario de carácter fenicio-púnico situado en lo que debió ser una isla boscosa en la desembocadura del Guadalquivir, convertida en la actualidad en una península, se menciona la aparición, en un recinto de carácter sacro, de una construcción de planta cuadrangular con numerosos material votivo de fines del VI o comienzos del V a C. En su interior se hallaron, junto a numeroso material etrusco, dos pies de bronce, (Corzo 1991:404), uno de ellos calzado con bota de punta levantada que pudo pertenecer a una figurita de "smiting god", según Ferrer $(2002,199)$.

En torno a un espacio al aire libre aparecieron diversas construcciones de planta rectangular de 3 a $5 \mathrm{~m}$. La mayoría de los materiales hallados en el interior de estas pequeñas construcciones se sitúan entre los s. IV-III a C. Entre ellos podemos destacar la mitad delantera de un pie en terracota que algunos autores proponen que correspondería a una estatua de madera (Blanco, Corzo 1983, 124; Moneo 2003, 62-66).

\section{La Cova des Meravelles (Gandía,} Valencia)

A pesar de que en las cuevas santuario de la región valenciana existen gran número de ofrendas y objetos rituales, sólo en la cueva de Gandía parece constatarse este tipo de ofrenda. Así, Gil Mascarell, recogiendo noticias anteriores, describe que entre la cerámica ibérica de esta cueva existen dos toscas representaciones de piernas humanas. (1975: 310 y 311). No sabemos, por no figurar reproducidas, si las piernas serían votivas o formarían parte de figuras completas (Prados 1991: 329).

\section{NeCRÓPOLIS}

Cabrera del Mar (Mataró, Valencia)

Contamos con un vaso de barniz negro en forma de pie calzado, aparecido en una tumba.
El tipo de ajuar, según recogen Pérez Ballester y Gómez Bellard $(2004,37)$, podría ser de un enterramiento masculino: escudo, soliferreum y espada; pátera, y crateriscos de barniz negro (Barberá, 1968: 103).

\section{Cabecico del Tesoro (Murcia)}

En esta necrópolis contamos con dos vasos de barniz negro y otro de factura local con forma de pie. Los vasos de barniz negro aparecieron en las tumbas T-328 y T-446, y el de factura local en la T-463. Este último, imita la forma de pie calzado con el mismo tipo de sandalia que los vasos similares que aparecen en la misma necrópolis. El ajuar de esta última tumba, fechada en el s. III a C., como nos recuerdan P. Ballester y G. Bellard, es de gran interés: vaso plástico en forma de gallo, seguramente púnico; vaso plástico en forma de granada, un timaterion con cabeza de Tanit; una jarrita, un ungüentario y una pequeña botella. Según Olmos (en Page 1984, 297), este conjunto evoca una ideología de ultratumba con huella de un posible ritual votivo de libaciones complejas. (Sánchez Meseguer y Quesada 1992: 367; Prados 1996: 279; Page, 1984: 129-130; Olmos, 1984, en Page; García Cano, et alii 1989: 129-131; Pérez Ballester y Gómez Bellard (2004, 37 .fig. 2.5)

\section{La Albufereta (Alicante)}

Vaso plástico de barniz negro, datado a finales del s. IV, aunque Pérez Ballester y Gómez Bellard consideran que debe revisarse su datación que ellos sitúan en la $2 / 2$ del s. III a C. (Rubio Gomis 1986: ; Prados 1996: 279; Pérez Ballester y Gómez Bellard 2004,33)

\section{La Serreta, Alcoy (Alicante)}

Contamos con un vaso plástico de imitación local, en forma de pie izquierdo calzado con sandalia, fragmentado, con decoración pintada, representando las cintas o correas de la sandalia, así como algunos signos estrellados. Apareció en la tumba 30 de la necrópolis recientemente excavada, según nos informan $P$. Ballester y G. Bellard $(2004,37)$. Se considera que se trata de una tumba rica, fechada provisionalmente en la $2 / 2$ del s. III a C. y perteneciente a una mujer, dadas las características de su ajuar: un timaterion con cabeza femenina; 9 fusayolas; 24 astrágalos o tabas; 9 pequeñas bolas de piedra; cuentas de collar; 2 sortijas y pendientes de plata y oro, 5 platos, dos tarros y una tinaja. (Prados 1996: 279; Moltó 2000, 21; Pérez Ballester y Gómez- Bellard 2004, 37 fig. 2,7).

Baza (Granada)

Colgante de piedra en forma de pie localiza- 
do en el interior de un recipiente cinerario, en la sepultura 27 de esta necrópolis. Aparentemente representa el pie izquierdo y se indica una "S" en su planta. Lucas destaca que la tumba, posiblemente femenina, conservaba también un fragmento de una cabeza de caballo en arcilla (Presedo 1982: 54-55; Prados 1996: 279; Lucas 2003: 205 y nota 11 )

\section{Necrópolis Púnicas}

No vamos a detenernos a analizar los hallazgos de las necrópolis púnicas, sólo señalar que también es frecuente su presencia tanto en la necrópolis de Villaricos (Almería) (Astruc 1951: 60) como de Puig des Molins (Ibiza) (Fernández, 1985: 149-175, Fernández 1992; González Prats 2004)

\section{HÁBITAT}

$\mathrm{Al}$ igual que veremos al hablar de las representaciones de aves, los ejemplares de pies aparecidos en poblados en un número elevado corresponden a los denominados "edificios singulares".

\section{Puntal dels Llops (Olocau, Valencia)}

En lo que se considera un edificio singular, apareció un vaso en forma de pie derecho calzado de barniz negro. Procede del Departamento 1. Los materiales corresponden al momento de destrucción del poblado, a fines del III o inicios del s. II a C. P. Ballester y G. Bellard nos recuerdan que en esta "habitación especial" aparecieron materiales como: cabezas humanas de terracota, interpretadas como imágenes de antepasados; dos timateria con cabeza de Perséfone/Tanit,; 38 pesas de terracota, pertenecientes a un telar; una balanza y juego de pesas de bronce, que ellos interpretan como un elemento de control de metales preciosos; abundante vajilla ibérica pintada de mesa; gran número de ánforas, contenedores de almacenamiento de productos agrícolas como cereal o aceite o vino, etc. (Bonet, Mata et alii 1981: 77-102; fig. 34; y lámina XVI; Pérez Ballester y Gómez Bellard 2004, 36 fig. 2,2)

\section{Los Villares de Caudete (Valencia)}

También en este caso podemos hablar de un edificio singular. Contamos con dos vasos plásticos de imitación local en forma de pie calzado, derecho e izquierdo que aparecieron en el Departamento 11, que puede considerarse un edificio singular dentro del poblado, tanto por su estructura, amplia habitación con soporte central que apoyaría en una plataforma circular de piedras planas, como por los materiales allí conservados, entre los que destacan: pesas de telar; ins- trumentos de labranza de hierro, gran número de contenedores: ánforas y tinajas, etc. Su cronología se situaría entre fines del III y comienzos del II, cuando el poblado es destruído (Pla 1980: 49-53; Prados 1996: 279; Pérez Ballester y Gómez Bellard 2004, 36 y 37) Fig. 2,6.

\section{San Miquel de Lliria (Valencia)}

En el Departamento 113 de este poblado, existe un fragmento cerámico decorado en el borde con una serie de estampillas del pie izquierdo, de dedos bien marcados, y una " $\mathrm{S}$ " rellenando la silueta que Bonet (1995: 259 y 433; lám. XXVI) compara con la estampilla de un asa procedente de Moluengo de Villargordo del Cabriel (Lucas 2003: 205, nota 11).

\section{Tornabous (Lleida)}

Contamos con un ejemplar de vaso plástico de barniz negro aparecido en un nivel de la $2 / 2$ del s. III a C: ( Cura Morera, 1992: 131; Pérez Ballester y Gómez Bellard, 2004, 33)

En el ámbito cultural celtibérico, no parece que las representaciones de pies sean tan frecuentes como en el ibérico, sin embargo, no podemos dejar de señalar algunas representaciones en arcilla pintada de rojo procedente de Numancia, calificadas como exvotos (no 5280 y 283 del catálogo celtíberos 2005)

\section{II- LAS REPRESENTACIONES DE AVES.}

Su aparición es muy frecuente en la Península Ibérica, tanto en el ámbito ibérico como celtibérico, y siempre vinculado a la divinidad femenina.

Como precedentes Orientalizantes, podemos citar, entre otros, las arracadas del tesoro de La Aliseda, Cáceres, con parejas de aves que parecen libar de una flor, reproduciendo el tema oriental del árbol de la vida, símbolo de la fecun-

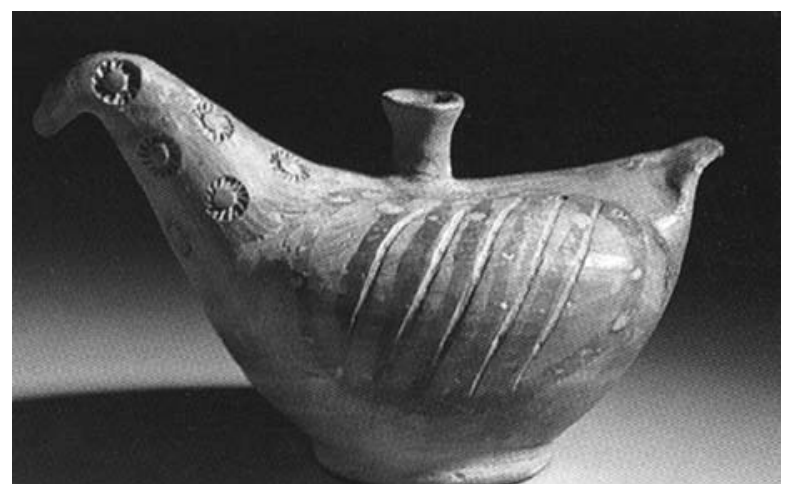

Figura 3- Vaso plástico en forma de paloma de El Amarejo (Albacete) Fot. $M^{0}$ de Cultura 
didad de la naturaleza (Olmos 1992, 86; Pereira 1999, 20) o la diadema de oro de Crevillente, Alicante, (González Prats, 1978: 354; Pereira 1999: 21) decorada con una serie de motivos repujados como palmetas, aspas y aves dispuestas en línea. En el llamado Bronce Carriazo (Olmos 1992, 69; Pereira 1999, 72; Jiménez Avila, 2002, 347), vemos la representación de una imagen de la divinidad femenina con peinado hathórico, entre dos prótomos de aves acuáticas, que forman una barca solar y que podrían simbolizar las aves migratorias, cuya presencia marca los ciclos estacionales y también la capacidad de viajar y volver del Más allá. Esta pieza, adquirida en el mercado de antigüedades, procedería de la zona de Sevilla, lo mismo que la conocida figurita de Astarté, que podemos relacionar con el interesantísimo santuario dedicado a esta divinidad en El Carambolo y objeto de nuevas excavaciones en los últimos años.

Asimismo, podemos mencionar el bronce del Museo de Sevilla, procedente también del mercado de antigüedades, que representa una figura femenina bifronte con las manos alzadas, se supone que con sendas aves, aunque falta la mano izquierda. Esta pieza ha sido publicada como el enmangue de un asador (Fernández Gómez, 1992-93,) o como clavija (Jiménez Avila, 2002, 408, fig. XLI).

En el mundo ibérico podemos señalar su presencia en distintos tipos de materiales y objetos: vasos plásticos, exvotos de terracota o bronce, orfebrería, pintura vascular, etc, Del mismo modo, la encontramos en poblados aunque, como veremos, casi siempre vinculada a los llamados "edificios singulares"; en santuarios o depósitos votivos y en necrópolis.

\section{Poblados}

\section{Margalef (Lleida)}

En una estancia principal del poblado, apareció un vaso en forma de ave, modelado a mano, en un contexto en donde, entre otros objetos, encontramos: tinajas y ánforas; piezas relacionadas con un telar, un molino, una hoz de hierro, vajilla de barniz negro, brazalete de pasta vítrea y vasos de imitación relacionados con libaciones o consumo de vino, vasitos caliciformes, etc. Por tanto, parece que nos hallamos ante un edificio singular, fechado a fines del s. III o inicios del II a C., donde se desarrollaron funciones relacionadas con el almacenamiento de excedentes, con actividades artesanales, como la textil, y posibles actividades rituales. (Junyent 1973, 91, fig. 1; Pérez Ballester y Gómez Bellard 2004, 40).
Coll del Moro (Gandesa, Tarragona) parece que se halló un vaso plástico en forma de paloma en un almacén junto a un taller de procesado y tejido de lino, que se abandona bruscamente a finales o inicios del s. III a C. (Rafel, Blasco y Sales, 1994; Pérez Ballester y Gómez Bellard 2004, 41)

\section{Coimbra (Jumilla, Murcia)}

En este caso se desconoce el contexto, al tratarse de excavaciones antiguas, de tres ejemplares de vasos plásticos en forma de paloma. (Molina Garcia et alii, 1976, 59-60; figs. 35-36, lám XX; Page 1984, 133, fig. 19, 4-5; Pérez Ballester y Gómez Bellard 2004, 41)

\section{SANTUARIOS Y DEPÓSITOS VOTIVOS}

\section{El Amarejo (Bonete, Albacete).}

En la parte superior del poblado ibérico apareció un complejo arquitectónico que consta de varias estancias y al que se atribuye una función sacra, así como una favissa o pozo sacro excavado en la roca (Alfaro, Broncano 1993; Blánquez 1996). En el departamento 3 del edificio, se localizaron objetos como pondera y fusayolas que podrían corresponder a un telar. En el departamento 4, que es una pequeña habitación cerrada y que se interpreta como destinada a almacén o venta de objetos de culto, se encontró un vaso plástico en forma de paloma, junto a centenares de vasos entre los que predominan los platos, páteras y tapaderas, todos sin usar, así como un pebetero con cabeza femenina (Broncano y Blánquez, 1985, 251-254, fig. 141, lám XXVII; Pérez Ballester y Gómez Bellard 2004,41 fig. 5,2)

En cuanto a la favissa, se trata de un pozo rectangular de $4 \mathrm{~m}$. excavado en la roca, donde se hallaron dos vasos en forma de paloma. Se trata de vasos pintados, uno de ellos con estampillas en forma de rosetas (fig. 3) y uno en forma de "sirena", junto a otras ofrendas como restos de telas, fusayolas, agujas de coser, objetos de adorno como agujones de bronce y marfil para el pelo, agujas de oro y bronce, fíbulas, un peine de madera, una placa de cinturón de plata con representación de un guerrero, así como restos de un cráneo humano que Broncano interpreta como intrusivo $(1989,63)$ pero que Oliver $(1995$, 40) contempla la posibilidad de que pudiera haber formado parte de un ritual de ofrenda y purificación. Los materiales se fechan entre mediados del IV a C. a fines del III o inicios del II a C. (Broncano, 1989, 113-114, 144, 170, figs. 42, 85, 126, láms LXXVIII, LXXXVII y C; Moneo, 2003, 111 ). 
Collado de los Jardines (Sta. Elena, Jaén)

En este santuario contamos con dos exvotos en bronce de oferentes femeninos (fig. 4) uno de ellos (Prados 1992, n ${ }^{0}$ 532, 216 y 341), representa una figura desnuda, con cinturón ajustado y tocado bajo, con ambos brazos levantados mostrando en la mano derecha un ave, mientras en la izquierda porta un fruto (y no sendas aves como por error cita Pereira $(1999,22)$. En el segundo caso, se trata de una figura vestida con una túnica larga, ajustada con cinturón a base de tiras muy finas, peinada con trenzas acabadas en bola y con un tocado bajo, que muestra en su mano derecha un ave, quizá un vaso plástico, mientras la izquierda está fragmentada. (Prados 1992, n ${ }^{\circ} 549,216$ y 342). Dadas las especiales dificultades que entraña la datación de este santuario, podemos considerar que los inicios de su culto podrían remontarse al s. V a C., aunque su momento de auge debió situarse durante los s. III y II a C, perdurando incluso después del cambio de Era (Prados 2004).

\section{La Quéjola (Albacete)}

En el interior del poblado se localizó un edificio singular compuesto por dos estructuras adosadas A y B, consideradas residencia y almacén y santuario para la distribución del vino, con una fecha de abandono de fines del V. a C. (Blánquez y Olmos 1993, 93). Del interior de la estructura B proceden, elementos textiles como dos telares de pared (Blánquez 1997: 228), armas, ánforas, cazuelas con decoración plástica de palomas en la zona del cuello, copas Cástulo, grandes vasijas, etc. De este edificio consideran sus excavadores que procedería el famoso timaterio (fig. 5)

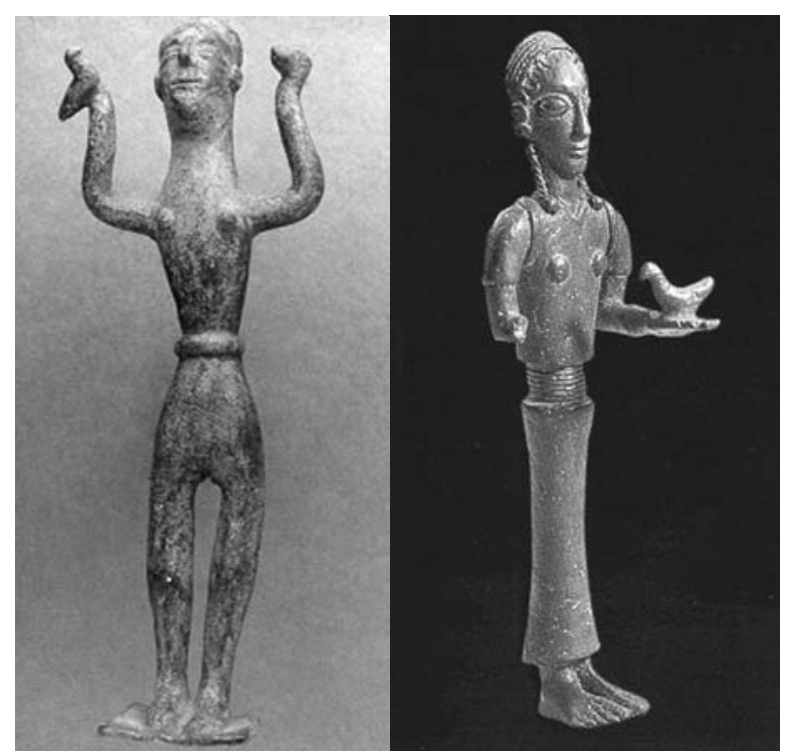

Figura 4- Exvotos en bronce procedentes del santuario de Collado de los Jardines con ofrendas de aves. Fotog. $M^{0}$ de Cultura encontrado por un particular antes de la realización de las excavaciones. Esta pieza se data a fines del s. VI y forma parte de un quemaperfumes ritual. El fuste antropomorfo que sirve de sustentación a la cazoleta representa a una figura femenina desnuda, peinada con dos trenzas que caen sobre los pechos. Los brazos, adornados con brazaletes, se hallan doblados hacia el frente y en la mano derecha sostiene una paloma. El puño izquierdo cerrado deja un orificio por el que se introduciría un objeto hoy desaparecido. Olmos considera que se trata de "una hetera o hieródula de la diosa de la fecundidad, de la Astarté/Afrodita o, mejor de su proyección ibérica"(Olmos 1991, 52; Prados 1996 b; Jiménez Avila, 2002, 401, fig. XXXII ).

\section{Cancho Roano ( Zalamea de La Serena, Badajoz) \\ En la llamada H-8 del Palacio-Santuario de} Cancho Roano A, del s. V a C., se recogieron numerosos objetos relacionados con los arreos y atalajes de caballos, así como jarros, calderos y otros recipientes también de bronce. En cuanto a la cerámica era casi exclusivamente de lujo e importación. Entre los bronces quizá los elementos más significativos sean las camas laterales de los bocados de caballos, entre los que destaca

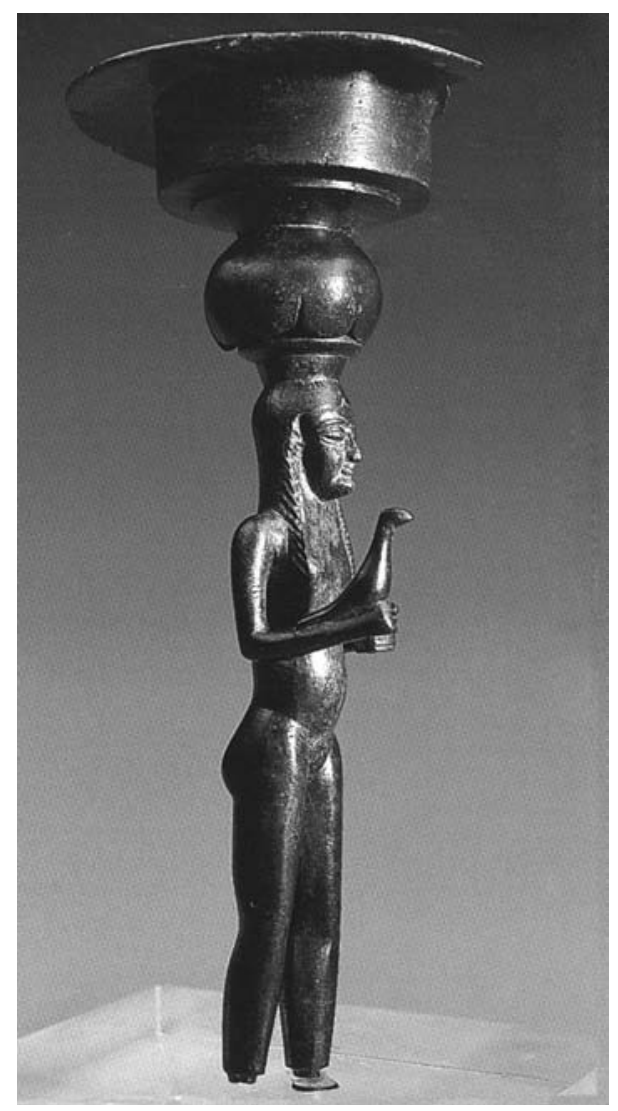

Figura 5- Timiaterio de La Quéjola (Albacete). Foto:J. Blánquez, Proyecto UAM. 
una placa totalmente calada que representa a un despotes bifronte que apoya sus pies sobre un cuerpo curvo semicircular rematado por las cabezas de sendos caballos y sobre sus brazos reposan dos aves (Celestino 2001, 37 y 62).

\section{La Serreta de Alcoy (Alicante)}

En la acrópolis del poblado se encuentra el santuario, y junto al mismo las nuevas excavaciones han permitido localizar distintas estructuras (Olcina et alii 1998; Esteban Cortell 1999, 138). Los exvotos en terracota, mayoritariamente femeninos, junto a cerámica ibérica y sigillata, lucernas romanas, sortijas de bronce, ungüentarios, etc se hallaron tanto en el santuario como en sus laderas. Destacan, asimismo, tres inscripciones de plomo, una de las cuales apareció en un recinto irregular junto a una pared y acompañada de una copa de cerámica, cuernas de ciervo y una palomita pintada de barro cocido.

En el poblado de La Serreta se documenta, además, en el llamado sector F, una estructura de carácter sacro (Grau 1996 a y 2000, 199 y s.s.), que Moneo $(2003,109)$ vincula a un culto suprafamilar en el que participarían las élites de la comunidad. Aquí es donde se localizó la famosa terracota que representa a una divinidad nutricia, a la que le falta la cabeza, amamantando a dos bebés, flanqueada por sendas aves, aunque se ha perdido una, acompañada a cada lado por una mujer y un niño, los del lado izquierdo músicos, tocan la doble flauta o aulós. En este mismo lugar se halló el kalathos "de la paloma y adormidera o granada" que ha sido relacionada con una divinidad asimilada a Tanit (Grau 2000, 200;) y con la reelaboración ibérica del motivo oriental del ave que guarda el árbol sagrado (Izquierdo et alii $2004,178)$, junto a vasos de prestigio o funcionalidad ritual decorados, como "el vaso de los guerreros", una matriz de orfebre, etc ( Moneo 2003, fig. IV).

\section{La Algaida (Sanlúcar de Barrameda,} Cádiz).

Ya nos hemos referido anteriormente, a este interesante santuario de carácter fenicio-púnico situado en la desembocadura del Guadalquivir, entre el río y el Lacus Ligustinus.

En torno a un espacio al aire libre aparecieron diversas construcciones de planta rectangular de 3 a $5 \mathrm{~m}$. La mayoría de los materiales hallados en el interior de estas pequeñas construcciones corresponde a los siglos IV-III a C. Entre otros materiales se hallaron unos 500 anillos de bronce, de los cuales más de 100 ofrecen el chatón decorado, algunos con motivos de aves. Corzo plantea que los paralelos más ilustrativos de estas representaciones pudieran haberse transmitido a través de las monedas, como las de Himera, y de aquí haber pasado a diferentes soportes (Corzo 2000), aunque tampoco podemos olvidar la enorme riqueza de fauna que posee este territorio, hoy ocupado por el Parque Natural de Doñana, donde existe una reserva de más de 100 especies de aves migratorias, que marcarían con su paso, las estaciones del año.

\section{Alhonoz ( Herrera, Sevilla)}

Situado en el valle medio del Genil, el hallazgo en este oppidum de un gran edificio, una favissa y un depósito cerámico, plantea problemas tanto cronológicos, con materiales desde inicios del s. VII a C. hasta quizá el II aC., como de interpretación, al no quedar clara la relación de las tres estructuras entre sí, ni la función de las mismas. En la posible favissa encontramos, entre los materiales antiguos, la mitad superior de una figura femenina, un thimaterio de bronce, una placa de plata con ojos, etc. junto a cientos de vasos apilados del s. III a C., entre ellos un timaterio cerámico con decoración plástica de paloma (López Palomo 1981 b, 72, fig. 23; Moneo 2003, 51, fig. IV. 6.5)

\section{Garvâo. (Alentejo, Portugal)}

En el depósito ritual de Garvâo, en el Bajo Alentejo, (Beirâo et alii 1985) aparece un vaso adornado con una representación plástica de un ave, que puede tener paralelos con el thymiaterium con decoración de palomas procedente del depósito votivo de Alhonoz, Sevilla al que nos acabamos de referir. Lo mismo que dos representaciones antropomórficas sobre placas de plata, que sus estudiosos identifican con un atributo de una divinidad femenina, (Tanit, Afrodita, etc) (López Palomo 1981: 72, fig. 23 y AlmagroGorbea y Moneo 2000, lám. 1, 5)

\section{NECRÓPOLIS}

\section{Cabezo Lucero (Rojales, Alicante)}

En el llamado punto 54 de esta necrópolis, considerado como deposición de ofrendas se localizó un ejemplar fragmentado de vaso plástico en forma de cabeza de pájaro pintada en rojo, junto a un calatos ibérico, tres fusayolas, 10 cuentas de collar, un ascos ático con cabeza de león, etc. Se fecha entre el 375 y el 350 a C. (Aranegui et alii, 1993, 223-225, fig. 61,3; Pérez Ballester y Gómez Bellard, 2004, 41)

También en el punto 62 de esta necrópolis se encontró, como parte del ajuar, un ascos ático en forma de pato decorado con bandas de ovas y palmetas y entre la ceniza 10 pequeñas semiesferas de oro, junto a cerámica y restos de cuentas 
de collar, un vasito caliciforme, etc (Aranegui. et alii, fig. 66, p. 228)

\section{Corral de Saus (Moixent, Valencia)}

Izquierdo plantea la posibilidad de que una serie de fragmentos de vasos plásticos, identificados como colas pudieran tratarse de colas de aves o de seres fantásticos como "sirenas" (1996, 251253, fig. 11, 2-7), posibilidad que también contemplan Pérez Ballester y G. Bellard $(2004,41)$

\section{Coimbra (Jumilla, Murcia)}

Un ejemplar de vaso plástico en forma de paloma apareció en la tumba 70, conocida por su pilar estela con los jinetes, gola con guerreros yacentes y toro superior. Se considera que podría tratarse de una rica tumba femenina, fechada a mediados del s. IV a C. (Iniesta et alii, 1987, 3637, fig. 11; Pérez Ballester y G. Bellard, 2004, 41) fig. 5.6.

\section{El Cigarralejo (Mula, Murcia)}

En la necrópolis aparecieron fragmentos correspondientes a distintos vasos en forma de paloma. Salvo el ajuar de la T-374, considerada masculina por las armas, fechada a fines del s. III o inicios del II a C., las otras tumbas con este tipo de vasos tienen ajuares simples y uno o dos vasos (Page, 1984, 134; Cuadrado, 1987, 159, 576; Pérez Ballester y G. Bellard 2004, 41 fig. 4 y 5)

\section{La Albufereta (Alicante)}

Encontramos figuras femeninas en terracota portando palomas en dos tumbas, al menos, de esta necrópolis. En la tumba 100 aparece una de estas terracotas sosteniendo a un niño y a una paloma, junto con un timaterio de cabeza femenina. De aquí procedería el famoso relieve en piedra de la pareja de alto rango social, en el que la mujer muestra un huso, elemento vinculado a su labor de hilandera, símbolo de su condición femenina, garante del hogar, mientras el hombre porta una lanza (Izquierdo et alii 2004, 183-184). La otra tumba destacable sería la 127 en la que aparecen distintas figuras femeninas en terracota con palomas y niños y en alguna de ellas se ha querido ver mujeres embarazadas. Asimismo, destaca "la gruta" en terracota, posible reproducción de una cueva-santuario, etc. (Rubio 1986, 215-218, figs. 97-98; Pérez Ballester y Gómez Bellard 2004, 44; Tortosa ed. 2004)

\section{Toya (Jaén)}

Proceden de esta necrópolis dos cajas cerámicas decoradas, con tapaderas con un asidero ornitomorfo, modelado sin excesivos detalles. La combinación de los semicírculos reproduce la visión en planta de una flor abriéndose, el aside- ro en forma de ave parece surgir del centro de una flor (Pereira 1999, fig.1). Esta necrópolis debe su fama a la impresionante cámara sepulcral hipogea y al variado ajuar que se rescató de su interior, así como a la colección de vasos ibéricos y áticos procedentes de otros enterramientos de menor monumentalidad. Su hallazgo casual en 1908 y su posterior expolio impiden que se conozcan sus estructuras y contextos arqueológicos.

Pereira vincula estas piezas de pequeño tamaño, con su adscripción tanto en la vida cotidiana como en las prácticas religiosas, con una mujer de alto rango que desempeñó un papel importante en el seno de la comunidad ibérica que vivió en Toya: el de sacerdotisa de una divinidad femenina (Pereira 199, 25 y 26)

\section{Cerro del Santuario, Baza (Granada)}

No podemos dejar de mencionar la conocida tumba de la necrópolis del Cerro del Santuario, en Baza, donde se halló junto a un rico ajuar compuesto por armas, cerámica decorada, etc. la conocida escultura entronizada utilizada como urna, que representa a una mujer de mediana edad ataviada con ricos ropajes y joyas, sentada en un trono alado, sosteniendo en una mano un pequeño pichón (Presedo 1973 y 1982.; Chapa y Madrigal 1997. Izquierdo y Prados 2005)

\section{Mundo Céltico}

El tema de las aves es también relativamente recurrente en el mundo céltico, aunque no tanto como en el púnico o ibérico. En el ámbito céltico es muy frecuente la representación de aves rapaces, carroñeras encargadas de la descarnación de los cadáveres. Lorrio (1987:345) recoge dos citas de autores clásicos relacionadas con esta cuestión. En la primera Silio Itálico $(3,340-343)$ refiriéndose a los celtíberos afirma:

Para éstos es un honor caer en el combate y un sacrilegio incinerar un cuerpo muerto de este modo. Pues creen que son retornados al cielo, junto a los dioses de lo alto, si el buitre hambriento devora sus miembros yacentes (traducc. Díaz-Regañón 1984: 61).

En la segunda Claudio Eliano (X, 22) nos informa: Los vacceos ultrajan los cuerpos de los cadáveres de los muertos por enfermedad ya que consideran que han muerto cobarde y afeminadamente, y los entregan al fuego; pero a los que han perdido la vida en la guerra los consideran nobles, valientes y dotados de valor y, en consecuencia, los entregan a los buitres porque creen que éstos son animales sagrados (traducc. De Olmos 1986: 218, nota 15$)$

Existen, además, diferentes representaciones iconográficas, especialmente en cerámica, aunque también en otro tipo de soportes, que nos ilustran sobre este aspecto. 
También en el mundo celtibérico tenemos constancia, aunque en proporción pequeña respecto a otros animales de mayor tamaño como equinos, bóvidos, ovicápridos, etc, del sacrificio de aves como ofrendas. Asimismo, se ha interpretado en este sentido un vaso de Numancia (ver Lorrio 1997: fig $126,1, \mathrm{c})$.

De igual modo, aparecen representaciones de aves con carácter ritual en el interesantísimo vaso de Arcóbriga estudiado por Marco Simón (1993, 2005). Este autor interpreta la imagen como una escena doble en la que aparecería un templo y en su interior un personaje coronado por un árbol y flanqueados por sendas aves de cola abierta, sobre las que se encontrarían unas serpientes cornudas.

Sabemos que las palomas, junto con los cuervos, se asocian también a los oráculos (Green 2001: 66) $Y$ en este mismo sentido C. Aranegui interpreta una escena aparecida en un fragmento de cerámica ibérica de San Miguel de Liria (dpto.16.núm 12) conocida con el nombre de "danza ritual", en el que un personaje encapuchado ofrece una pequeña ave a un hombre portador de un puñal y una lanza (Aranegui, 1996: 101, fig.12)

Existen asimismo, paralelos de aves, más o menos semejantes, en algunos de los "depósitos" de la Segunda Edad del Hiero peninsular Entre ellos podemos destacar, por haberlo estudiado directamente, una de las placas del Tesoro de Salvacañete, (Cuenca) donde se observa el óvalo de un rostro humano, un ave con la cola abierta, alejada de la iconografía de las aves carroñeras y la representación de una abeja. (Arévalo et alii 1998 y Arévalo; Marcos; Perea y Prados e.p.) Podemos señalar su presencia en varios de los "tesoros" estudiados por Raddatz (1969). Como algunas fíbulas de Driebes, Guadalajara, (lám 8, 10); en la fíbula de Mogón (Jaén) (lám 27, 1); en la plaquita perforada de Pozoblanco, muy semejante a la de Salvacañete, (lám 47,5); o las rapaces en el pectoral de Chao de Lamas lám. 90 y 91 1,b). El pendiente de Santiago de la Espada (Jaén) donde aparece un personaje femenino portando palomas.

En las plaquitas aureas de La Serradilla, (Cáceres) encontramos dos parejas afrontadas de aves (Berrocal 1989, fig. 2, 4 y 5) y en la tercera, cuyos motivo iconográficos considera su estudioso como: pareja de figuras alargadas, ... quizá bellotas (Berrocal 1989, 285), creo que podría identificarse el mismo motivo de la pareja de aves, pero esta vez vista de perspectiva cenital.

El ave también ha sido considerado atributo de una divinidad femenina. Olivares (2002: 222), recoge la identificación del ave con la divinidad femenina Nantosuelta en la famosa Fonte do Idolo de Braga, próxima a las murallas de la ciu- dad romana de Bracara Augusta, donde también se representaría a su pareja masculina Sucellus. Este mismo autor comenta que el ave, como atributo de Nantosuelta, aparece en otros casos, como el altar de Saaburg o el de Séller, en territorio de los Németos, aunque siempre parece tratarse de cuervos. Recoge, asimismo, la mención de Green (1992: 157-158), que destaca la relación entre el ave y la diosa que se muestra en una de las placas del Caldero de Gundestrup, en la que la divinidad sostiene al animal con su pulgar (Olivares 2002, nota 651). Del mismo modo Nantosuelta ha sido identificada con una corneja. Los pájaros también se asocian en el mundo céltico a la curación y a la creencia de que se volvía a la vida en el Más Allá (Green 2001: 66) y en concreto representado en las aves migratorias que cada año emigraban a zonas más cálidas regresando en Primavera.

\section{INTERPRETACIÓN}

Ya hemos visto cómo la presencia de aves se documenta tanto en depósitos votivos y santuarios, como en necrópolis y "edificios singulares" en los poblados, donde posiblemente tengamos que ver aunadas las funciones de almacenamiento de excedentes, actividades artesanales, y en particular las de carácter textil dado su permanente asociación a elementos relacionados con los telares, junto a posibles rituales de diversa naturaleza.

Las aves, sobre todo las palomas, pero también las acuáticas, sabemos que son el símbolo de una divinidad femenina, tanto de origen oriental, Astarté o Tanit, como griego, Afrodita, divinidad, por otra parte, con muchas connotaciones orientales. Algunos autores la consideran sobre todo, descendiente de Astarté. A Afrodita se la representa acompañada de sus animales como el delfín, el macho cabrío, el cisne, y la paloma, simbolizando su dominio sobre el mar, la tierra y el cielo. Como diosa del cielo viaja por el aire en carros de cisnes y gansos y se sienta sobre un trono de cisnes. Como diosa de la tierra, destaca en su aspecto fértil, a través de la lluvia reúne el cielo con la tierra y hace que de las semillas de la tierra humedecida brote la nueva vegetación . Pero quizá la imagen más común a todas estas divinidades femeninas (Astarté, Afrodita, Tanit) sea la paloma. (Baring y Cashford 2005, 410),

En muchos de los lugares donde aparecen representaciones de aves hemos visto que también aparecen los pebeteros de arcilla con cabeza femenina que, en general, suelen asimilarse a Deméter y su hija Perséfone ( o simplemente Core, "doncella"). 
La imagen de Deméter ("la verde", "la que trae la fruta" y "las estaciones") suele aparecer coronada de espigas de trigo o sosteniendo el trigo entre sus manos. Su presencia se invocaba en la siega y la siembra y sus fiestas se celebraraban al cambiar las estaciones, en primavera y otoño el tiempo de la muerte y el renacimiento del trigo. Baring y Cashford $(2005,418)$ nos recuerdan que a diferencia de su bisabuela Gea, Deméter no es la diosa de toda la tierra, sino sólo del aspecto nutricio de la misma.

Todas estas cuestiones relativas a diferentes divinidades femeninas con atributos y características muy semejantes podemos rastrearlas, en su proyección ibérica, a través de las representaciones de aves o pebeteros con cabezas femeninas. Es la divinidad que aparece transportada por las aves acuáticas, que simbolizan el cambio de las estaciones en el bronce Carriazo, o la divinidad nutricia que aparece en La Serreta de Alcoy flanqueada por aves y músicos donde su presencia, en lo que debió ser un edificio singular en el poblado, viene justificada por la necesidad de proteger y bendecir con su presencia las actividades que regirían la vida del poblado.

Los vasos plásticos en forma de paloma, como han puesto de manifiesto Pérez Ballester y G. Bellard (2004), permitirían un tipo de libaciones relacionadas con esta divinidad femenina, cuya presencia, por tanto, encaja tanto en los enterramientos formando parte de ajuares de segmentos de la población con un peso económico y social destacable, como en los santuarios o depósitos votivos. Los estudios sobre el género y la edad de las personas cuyo ajuar suele acompañarse de estas representaciones, en general vasos plásticos, todavía no permite aventurar si existe un sesgo que pudiera hacernos pensar que era mayoritario el numero de mujeres, por ejemplo, que se hacían acompañar al más allá por estas representaciones. Lo que sí parece claro es que tanto en los exvotos en bronce como en terracota, nos encontramos con que las palomas acompañan o las ofrecen, únicamente mujeres, quienes posiblemente entregarían estos animales como ofrendas a la divinidad. Del mismo modo que es una mujer, La Dama de Baza, la que sujeta en su mano cerrada un pichón.

No hemos incluido en nuestro breve estudio, por resultar excesivo para un artículo de este tipo, las representaciones de aves en la pintura vascular de Levante, que tan bien ha estudiado en los últimos años T. Tortosa y a cuyos trabajos podemos remitirnos (Tortosa 2004 a y b; 1998, etc.). Pero también en estos casos la presencia del ave habría que relacionarla, junto a la roseta y a los símbolos vegetales, con esa divinidad femenina cuyos atributos y orígenes podemos rastrear, pero cuyo nombre y características exactas, en su proyección ibérica, no podemos determinar.

¿Qué relación guardan las representaciones de pies con las aves? Hemos visto que en primer lugar, su presencia, aunque mucho menos frecuente que las aves, también suele repetirse en necrópolis con ajuares relevantes, en santuarios o en edificios singulares en los poblados. Comentamos al principio de estas líneas que la pieza de bronce que estamos estudiando (fig. 1) es la única que conocemos donde aparecen juntas ambas imágenes. Sin embargo, Lucas (2003: 199) al hablar de una de las piezas del Cigarralejo (fig. 2) relacionaba el triángulo, destacando su condición de emblema ancestral de la vida, con uno de los múltiples símbolos anicónicos alusivos de las divinidades Astarté y Tanit. La hiedra, representada también en este bloque trapezoidal, sería el recurso para mostrar, a través de una planta perenne, la inmortalidad y el poder regenerador de las grandes diosas de la Naturaleza. En cuanto a los pies desnudos, los vinculaba con una deidad como Némesis a la que se asocian múltiples epítetos vinculados con la representación de pies, como plantea Canto en su estudio sobre las placas de Itálica (Canto 1984), destacando asimismo, la propuesta de que la Tanit norteafricana incorporase en su bagaje el carácter de Némesis, así como los epítetos de las dedicaciones, entre ellas su vinculación con la Dea Caelestis. Es esta última divinidad la que tenemos constatada en el santuario de Torreparedones, donde la pieza más conocida es una pequeña cabeza de muy buena talla, cubierta posiblemente con un velo, en cuya frente se grabó una inscripción a la Dea Caelestis, la divinidad que recibiría culto en el santuario en el siglo I a.n.e. Marín Ceballos (1994), ya defendió que esta diosa, que los romanos asimilaron a Juno, se correspondería con la Tanit del panteón cartaginés. Los rasgos de marcado carácter púnico de este santuario han sido puestos en evidencia también a través del estudio de I. Seco (1999) sobre el culto betílico desarrollado en el mismo. Por todo ello, parece plausible que en Torreparedones se desarrollase un culto o bien a la propia Tanit, o bien a una divinidad indígena con rasgos y atribuciones semejantes, una divinidad propiciadora de la salud y de la fecundidad (Marín y Belén 2003: 178). En este sentido es importante recordar la existencia de algún exvoto (Cunliffe y Fernández Castro 1999: fig 6.4 y 6.39) donde parece clara la intención de representar a una mujer embarazada. Todas estas características permiten plantearnos la existencia de un culto predominantemente femenino, en el que la participación de las mujeres no se limitaría a la mera deposición de ofrendas, sino a un 
papel más activo en el desarrollo del culto. De esta forma resulta muy ilustrativa la conocida escena de libación, esculpida en un sillar de esquina procedente de este yacimiento, aunque sin un contexto claro, en el que dos mujeres parecen verter el líquido contenido en un vaso caliciforme- forma habitual en los santuarios ibéricos que sostienen entre ambas. A la derecha de las mismas se representa una columna con fuste acanalado acabado en un capitel en forma de león. Esto ha hecho pensar, a distintos autores, que pudiera ser una representación de la fachada del propio templo, o incluso una tumba, mientras que I. Seco (1999: 147), por su parte, interpreta el conjunto como una escena de culto betílico. (Izquierdo y Prados 2005)

Estos rasgos, vinculados a una divinidad relacionada con la fecundidad y con aspectos salutíferos, están muy presentes en muchos de los santuarios del ámbito ibérico. En este sentido, podríamos comprender nuestro exvoto de bronce. La unión del pie con el ave, símbolo de la divinidad y la fertilidad, tenemos que relacionarla con la dicotomía muerte/vida, con el paso al Más Allá. No olvidemos que en esta pieza, el ave mira en sentido contrario al del paso del pie. De igual modo que las representaciones de pies o sandalias aladas, localizadas en tumbas griegas, servían al difunto para facilitar su viaje hacia el Hades. Con el sentido de rito de paso encontramos huellas de pies dejadas por los peregrinos en recuerdo de las fatigas del viaje, los peligros del camino, con función de profilaxis y propiciación y el deseo, en última instancia, de fijar una presencia ideal en el santuario (Guarducci, 1942-43, Prados 1998, 185).

En definitiva, cualquiera que fuese el carácter, temporal, transitorio o definitivo del viaje que se fuera a emprender, la presencia de la divinidad garantizaba la llegada a su destino.

\section{Bibliografía}

ALFARO, M.; BRONCANO, S. (1993): "Estado actual de las excavaciones en El Amarejo", en Blánquez, J. et alii (Coords) Arqueología en Albacete: 131-144

ALMAGRO-GORBEA, M y MONEO, T (2000): Santuarios urbanos en el mundo ibérico. R.A.H. Madrid

ARANEGUI GASCÓ, C (1996): "Signos de rango en la sociedad ibérica. Distintivos de carácter civil o religioso", en Revista de Estudios Ibéricos, 2. Madrid: 91-121

- (Ed) (1997): Damas y caballeros en la ciudad ibérica. Las cerámicas de Edeta-Liria. Valencia

ARANEGUI, C. et alii (1993): La nécropole ibérique de Cabezo Lucero (Guardamar del Segura, Alicante). Collection de la Casa de Velásquez, 41. Madrid-Alicante.

ARÉVALO, S; PRADOS, L; MARCOS, C y PEREA, A
(1998):" El origen votivo del tesoro de Salvacañete (Cuenca)", Actas del Congreso Internacional, Los Iberos Príncipes de Occidente. Barcelona: 255-263

ASTRUC, M. (1951): La necrópolis de Villaricos, en Informes y memorias. Madrid.

BARBERÁ FARRÁS, J. (1968): "La necrópolis ibérica de Cabrera de Mar" Ampurias, XXX: 97-150

BARING, A y CASHFORD, J (2005): El Mito de la diosa Ed. Siruela.

BEIRAO, C.M. et alii (1985): "Depósito votivo de II Idade do Ferro de Garvâo” en O Arqueologo Português. Vol 3: 45135.

-(1987): "Um depósito votivo da II Idade do Ferro no Sul de Portugal, e a suas relaçoes com as culturas da Meseta." Studia Paleohispanica. (IV CL y CP) Veleia 2-3; 207-221.

BERROCAL-RANGEL, L . (1989):'Placas áureas de la Edad del Hierro en la Meseta Occidental", Trabajos de Prehistoria 46: 279-291.

BLÁNQUEZ, J y OLMOS, R (1993): "El Poblamiento ibérico antiguo en la provincia de Albacete. El timiaterio de la Quéjola (San Pedro) y su contexto arqueológico", Arqueología en Albacete, en Blánquez, Sanz y Musat (eds), Arqueología en Albacete. Madrid-Toledo: 85-110.

BONET, H. (1995): El Tossal de Sant Miquel de Lliria: la antiagua Edeta y su territorio. Valencia

BONET, H y MATA, et alii; (1981): El poblado ibérico del Puntal dels Llops (Olocau, Valencia), en Serie de Trabajos Varios del S.I.P., 71. Valencia

BRONCANO, S. (1989): El depósito votivo de El Amarejo (Bonete, Albacete). E.A.E. 156. Madrid.

BRONCANO, S y BLÁNQUEZ, J. (1985): El Amarejo (Bonete, Albacete) E.A.E. 139. Madrid

CABALLERO, A y MENA, P. (1987):'Los exvotos ibéricos del oppidum de Alarcos" XVIII CNA Zaragoza: 615-633

CANTO, A (1984): "Les Plaques votives avec plantae pedum d'Italica: un essai d'interpretation" Zeitschrift für Papyrologie und Epigraphik, 54. Bonn: 183-195

CELESTINO, S (1997): "Santuarios, centros comerciales y lugares sacros", en "Espacios y lugares cultuales en el mundo ibérico,", Quaderns de Prehistòria i Arqueologia, de Castelló, 18: 359-389.

- (2001): Cancho Roano. Mérida.

CORZO, R (1991): "Piezas etruscas del santuario de La Algaida (Sanlúcar de Barrameda, Cádiz)", en Remesal (coord.)La presencia de material etrusco en la P. Ibérica. Barcelona

(2000): "El santuario de La Algaida (Sanlúcar de Barrameda, Cádiz) y la formación de sus talleres artesanales", fornadas fenicio-púnicas, Ibiza: 147-181.

CUADRADO, E (1950): Excavaciones en el santuario de El Cigarralejo (Mula, Murcia). Informes y Memorias de la J.S.E.A. Madrid.

-(1987): La necropolis ibérica de El Cigarralejo (Mula, Murcia)B.P.H. XXIII. G.S.I.C. Madrid.

CUNLIFFE, B; FERNÁNDEZ CASTRO, Mㅜ C. (1997): The Guadajoz Project. Andalucia in the first millennium B. C. I. Torreparedones and its hinterland. Oxford.

CURA MORERA, M (1992): “Dos vasos plástics de vernis 
negre apareguts a Tornabous", Gala, 1: 131-134

CHAPA, T (1998): "Los Iberos y su espacio funerario", en Los Iberos, príncipes de Occidente. Barcelona: 109-120

CHAPA, T. y MADRIGAL, A. (1997): "El sacerdocio en época ibérica", SPAL 6: 187-203

FERNÁNDEZ, J. (1985): "La Necrópolis de Puig des Molins (Ibiza): Nuevas perspectivas", Aula Orientalis, 3:149-175.

- (1992): Excavaciones en la necrópolis de Puig des Molins. Las campañas de Román (Ferrer. Ed. Bovern Balear)

FERNÁNDEZ CASTRO, M ${ }^{\mathrm{a}}$ C. y CUNLIFFE, Barry W. (2002): El Yacimiento y el santuario de Torreparedones. B.A.R. International Series 1030.Oxford.

FERNÁNDEZ GÓMEZ, F. (1992-93): "Un asador excepcional y un excepcional conjunto de asadores del Bajo Guadalquivir", Tabona, vol VII-II: 465-480

FERRER, E. (2002): “Topografía sagrada del Extremo Occidente: santuarios, templos y lugares de culto en la Iberia púnica", en Ferrer (Ed) Ex Oriente Lux: Las religiones orientales antiguas en la Peninsula Ibérica. Spal Monografias II. Sevilla: 185-217

GARCÍA CANO, C et alii (1989): "Las cerámicas campanienses de la necrópolis ibérica del Cabecico del Tesoro (Verdolay, Murcia) Verdolay, 1: 117-188.

GIL MASCARELL, M. (1975): "Sobre las cuevas ibéricas del País Valenciano. Materiales y problemas" PLAV (Saguntum) XI: 281-333

GONZÁLEZ PRATS, A (ed) (2004): El mundo funerario. Alicante

GRAU, I. (1996): "Estudio de las excavaciones antiguas del 1953 y 1956 en el poblado ibérico de La Serreta" Recerques del Museu d'Alcoi 5: 83-119

GREEN, M (2001): Mitos Celtas. Ed. Akal .

-(2001): Dying for the Gods. Human Sacrifice in Iron Age and Roman Europe.

GUARDUCCI, (1942-43): "Le impronte del Quo Vadis e monumenti affini, figurati ed epigrafici" Rendiconti della Ponti. Acad.. Rom. D'Archeologia, 19: 305-344 .

INIESTA, A et alii (1987): Excavaciones arqueológicas en Coimbra del Barranco Ancho. La sepultura 70 de la necrópolis del poblado. Murcia

IZQUIERDO, I (1996): "Reminiscencias mediterráneas en cerámica ibérica. El ejemplo del Corral de Saus (Mogente, Valencia) en Archivo Español de Arqueología, 69: 239-262

- (2003): La ofrenda del vaso sagrado en la Cultura Ibérica, Zephyrus, LVI, 117-135.

IZQUIERDO, I et alii (20004): Diálogos en el país de los Iberos. Madrid

IZQUIERDO, I y PRADOS, L (2005): "Espacios funerarios y religiosos en la cultura ibérica: lecturas desde el género en arqueología" en SPAL 13

JIMÉNEZ AVILA, J. (2002): La toreútica orientalizante en la Peninsula Ibérica. R.A.H. Madrid.

JUAN, A. DE; FERNÁNDEZ, M; CABALLERO, A. (1994): "El yacimiento íbero-medieval de Alarcos", en Arqueología en Ciudad Real. Jornadas de Arqueología de la Universidad Autónoma de Madrid. Madrid: 143-165

JUNYENT, E. ( 1973):"Los materiales del poblado ibérico de
Margalef, en Torregrossa (Lérida)", Pyrenae,8: 89-132

LANTIER, R. (1917): El santuario ibérico de Castellar de Santisteban. Madrid

LÓPEZ PALOMO, (1981 ):"' Alhonoz. Excavaciones de 1973 a 1978". N.A.H. 11: 33-189

LORRIO, A.J. (1997): Los Celtíberos. Complutum,extra 7. Madrid.

LUCAS, R (1981): "Santuarios y dioses de la Baja Época Ibérica", Actas Mesa Redonda La Baja Época de La Cultura Ibérica. Madrid: 233-291

(2003): "Sobre el sexo de los dioses: las divinidades escondidas entre los exvotos de "El Cigarralejo" (Mula, Murcia)", Boletín de la Asociación de Amigos de la Arqueología, vol 42. Madrid, 2002-2003: 195-210

MARCO SIMÓN, F (1993): "Iconografía y religión celtibérica: reflexiones sobre un vaso de Arcóbriga", en Homenatge a Miquel Tarradell, Barcelona : 537-552

-(2005): "Religión Celta y Celbética" Los Celtiberos. Solia. 213-222.

MARÍN CEBALlOS, Mª C. ( 1994):: “ Dea Caelestis en un santuario ibérico",en González Blanco et alii (coord), El mundo púnico. Historia Sociedad y cultura: 217-225. Murcia.

MARÍN CEBALLOS , M $M^{\mathrm{a}}$ C. y BELÉN, Ma (2002-2003): "En torno a una dama entronizada de Torreparedones", en Homenaje a E.Ruano. Boletín de la Asociación de Amigos de La Arqueología, 42: 177-194.

MOLINA GARCÍA, J. et alii (1976): Coimbra del Barranco Ancho (fumilla, Murcia). Trabajos Varios del S.I.P., 52. Valencia

MONEO, T. (2003): Religio ibérica, Santuarios, Ritos y Divinidades siglos VII-I a.C., Biblioteca Arqueológica Hispana, 20, Madrid..R.A.H.

MORENA LÓPEZ, J.A. (1989): El santuario ibérico de Torreparedones (Castro del Rí-Baena, Córdoba). Córdoba

-(1997): "Los santuarios ibéricos en la provincia de Córdoba" QPAC 18: Espacios y lugares cultuales en el mundo ibérico. Castellón: 269-298.

NICOLINI, G et alii (2004) El Santuario ibérico de Castellar. Jaen, Junta de Andalucía

OLCINA, M. et alii (1998): "Nuevas aportaciones a la evolución de la ciudad ibérica: el ejemplo de La Serreta", en Aranegui (Ed): Los Iberos. Príncipes de Occidente. Estructuras de poder en la Sociedad Ibérica. Actas del Cong. Int. Barcelona: 35-46

OLIVARES, J.C. (2002):Los dioses de la Hispania Céltica. Madrid OLIVER, A (1995): "Acerca de los restos humanos localizados en los poblados ibéricos", Arx 1: 35-41

OLMOS, R (1991): "Broncística fenicia y orientalizante en el sur peninsular y en Ibiza. Una aproximación iconográfica y simbólica", en Producciones artesanales fenicio-púnicas. VI Fornadas de Arqueología Fenicio-Púnica . Ibiza: 41-64.,

OLMOS, R (Ed) (1996): Al otro lado del espejo. Aproximación a la imagen ibérica. Lynx. Madrid

OLMOS, R y SANTOS, J. A. (Eds) (1997): Iconografia Ibérica, iconografia itálica: propuestas de interpretación y lectura. Madrid.

OLMOS et alii (1999): Los Iberos y sus imágenes. Edición en Cdrom. Micronet S.A./CSIC Madrid.

OLMOS, R; TORTOSA, T e IGUACEL, P (1992): La sociedad 
ibérica a través de la imagen. Madrid

PAGE, V (1984): Imitaciones de influjo griego en la cerámica ibérica de Valencia, Alicante y Murcia. Iberia Graeca, 1. C.S.I.C. Madrid.

PEREA, A. (1991): Orfebrería prerromana. Madrid

PEREIRA, J ( 1999): "Recipientes de culto de la necrópolis de Toya", Archivo Español de Arqueología, 72: 16-30

PÉREZ BALLESTER, J. y BORREDÁ MEJÍAS, (2004): "La Carraposa (Totgl'I Corbera-Llanera de Ranes). Un lugar de culto ibérico en el Valle de Canyoles (La Costera, Valéncia)" Madrider Mitteilungen 45: 274-319

PÉREZ BALLESTER, J. y GÓMEZ-BELLARD, C (2004.): "Imitaciones de vasos plásticos en el mundo Ibérico", La Vajilla ibérica en época helenística (siglos IV-III al cambio de Era). Madrid. Collection de la casa de Velázquez volumen $\mathrm{N}^{\circ} 8$.

PLA BALLESTER, E. (1980): Los Villares (Caudete de las Fuentes, Valencia)Serie de Trabajos Varios del S.I.P., 68 Valencia

PRADOS TORREIRA, L. (1991): "Los exvotos anatómicos del santuario ibérico de Collado de los Jardines (Sta. Elena, Jaén)" Trabajos de Prehistoria, 48: 313-332

-(1992): Exvotos Ibéricos de bronce del Museo Arqueológico Nacional. Madrid.

-(1996a): "Los ritos de paso y su reflejo en la toréutica ibérica", Coloquio Internacional: Iconografia Ibérica, Iconografia Itálica. Madrid: 273-282.

- (1996b): "Los bronces figurados como bienes de prestigio" en R.Olmos y P. Rouillard, eds, Formes archaïques et arts ibériques. Casa de Velásquez. Madrid: 83-94

- (1998): "Los santuarios de época ibérica: origen e implantación territorial" en Pearce y Tosi. B.A.R. Int Ser 717: 184-186.

-(2004): "D. Juan Cabré y su aportación al conocimiento de los exvotos ibéricos de bronce", en J. Blánquez y B. Rodríguez (Eds) El arqueólogo fuan Cabré. La fotografia como técnica documental. Madrid: 337-350

PRESEDO, F (1973): "La Dama de Baza" Trabajos de Prehistoria 30: $151-216$

(1982): La necrópolis de Baza. Informes y memoria de la J.S.E.A.
Madrid

RADDATZ, (1969): Die Schatzfunde der Iberischen Halbinsel. Berlín RAFEL, N; BLASCO, M. y SALES, J (1994): "Un taller ibérico de tratamiento de lino en el Coll del Moro de Gandesa (Tarragona), Trabajos de Prehistoria, 51,2: 121136

RUBIO GOMIS, F (1986): La necrópolis ibérica de La Albufereta de Alicante (Valencia, España). Academia de Cultura Valenciana, Serie Arqueológica, 11. Valencia.

SÁNCHEZ MESEGUER, J. Y QUESADA, F (1992): “ La necrópolis ibérica del Cabecico del Tesoro, (Verdolay, Murcia)". Congreso de Arqueología Ibérica: Las necrópolis. Madrid: 349-397

SECO SERRA, I (1999): "El betilo estiliforme de Torreparedones", Spal, 8: 135-158

TORTOSA ROCAMORA, T. (1996): "Imagen y símbolo en la cerámica ibérica del Sureste", Olmos, R (Ed.) Al otro lado del espejo. Madrid, 145-162.

- (1998): "Los grupos pictóricos en la cerámica del Sureste y su vinculación con el denominado estilo ElcheArchena", en Aranegui (coord.) Actas del Congreso Internacional, Los Iberos Príncipes de Occidente. Barcelona

TORTOSA (Coord) (2004): El Macimiento de La Alcudia: pasado y presente de un enclave ibérico. Anejos de AEspA XXX. Madrid.

TORTOSA, T. Y SANTOS, J.A. (Eds) (2003): Arqueología e Iconografia. Indagar en las imágenes. Lerma di Bretschneider. Roma

VAQUERIZO, D (1997): "Testimonios de religiosidad ibérica en territorio de la provincia de Córdoba" QPAC 18, Espacios y lugares cultuales en el mundo ibérico. Castellón: 297-328

V.V.A.A. (1997): Celtiberos, tras la estela de Numancia. Catálogo de la exposición. Sori.. 